\title{
An Indirect Method of Estimating Maturation Rates of Cohorts of Capelin (Mallotus villosus)
}

\author{
J. E. Carscadden, G. H. Winters and D. S. Miller \\ Fisheries Research Branch, Department of Fisheries and Oceans \\ Northwest Atlantic Fisheries Centre, P. O. Box 5667 \\ St. John's, Newfoundland, Canada A1C $5 \times 1$
}

\begin{abstract}
A method of calculating age-specific maturation rates for capelin (Mallotus villosus) off southern Labrador and northeastern Newfoundland from catch-per-unit-effort data is presented. The data indicate that most of the capelin have matured at age 4. Underestimates of the instantaneous rates of either natural mortality or spawning mortality result in overestimation of the proportions of mature capelin by age-group, and overestimates of these mortality rates result in underestimation of the proportions of mature fish. In all cases, the percent error in proportions of mature capelin by age-group is considerably less than the percent error in the natural mortality or spawning mortality rate.
\end{abstract}

\section{Introduction}

The capelin stocks of the Northwest Atlantic were subjected to exploitation on an unprecedented scale during the 1970's, with catches in excess of 200,000 (metric) tons during $1973-77$ and peak catches exceeding 360,000 tons in 1975 and 1976 (NAFO, 1984). Initially, the capelin fisheries in NAFO Subareas 2 and 3 were regulated by catch quotas which were based on crude predator-prey models (Winters and Carscadden, 1978). Subsequently, the quotas were derived from biomass estimation procedures which were based on either acoustic surveys or sequential computation models (Carscadden and Miller, MS 1979; Miller and Carscadden, MS 1979). The sequential computation models require estimates of a variety of population parameters, including age-specific and time-specific maturation rates. In addition, estimates of annual maturation rates are necessary for prediction of biomass levels of mature capelin which are available to the coastal fisheries. Direct estimates of annual maturation rates of capelin are difficult to obtain due to the segregation of mature and immature fish and also to the nature of the commercial fisheries which are based mainly on mature fish. In this paper, a method of calculating annual age-specific maturation rates from catch-per-unit-effort data for the capelin fisheries off southern Labrador and northeastern Newfoundland is presented.

\section{Methodology}

Although there is little direct information on the seasonal migration patterns of capelin in NAFO Divisions $2 \mathrm{~J}$ and $3 \mathrm{~K}$ (Fig. 1), some researchers (Kovalyov and Kudrin, 1973; Seliverstov and Serebrov, MS 1979) have suggested a general overwintering migration from Div. 2J to Div. 3K during the autumn. This conclusion was based mainly on the temporal and spatial distributions of catches by fishing vessels, complemented by research vessel data. Because there are no offshore spawning areas in Div. 3K, it may be inferred

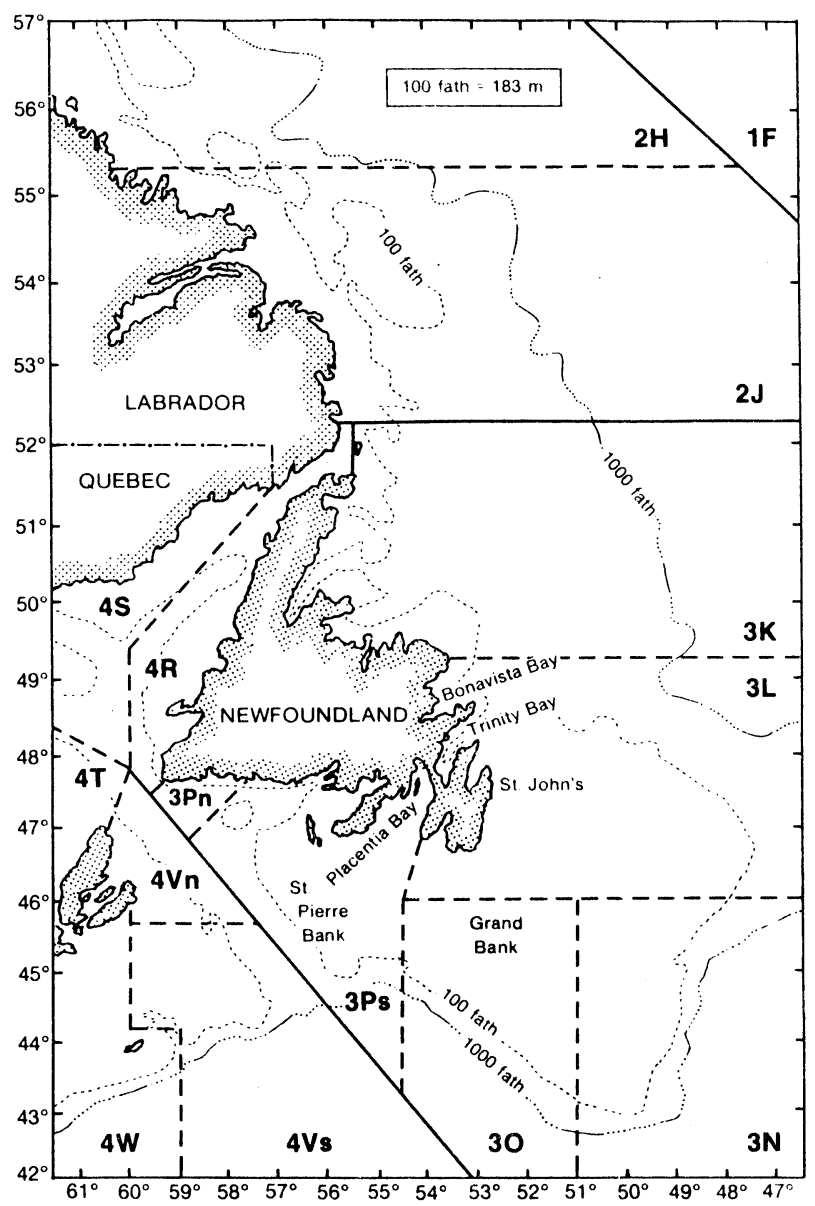

Fig. 1. Map showing NAFO Divisions referred to in the text. 
that some of the migrating fish are mature and will spawn on the beaches of northeastern Newfoundland (Div. 3K) in the subsequent year. Sampling data, on file at the Northwest Atlantic Fisheries Centre, St. John's, Nfld., indicate that more than $99 \%$ of the offshore catches (age 2 and older) in Div. 2J and 3K during 1978 and 1979 were maturing fish. Furthermore, the similarity of the age compositions of offshore catches in Div. $2 \mathrm{~J}$ and $3 \mathrm{~K}$ in the autumn to those of spawning capelin on the inshore beaches of Div. $3 \mathrm{~K}$ in the following summer during the 1973-77 period (Table 1) indicates that a large proportion of the offshore catches are maturing or mature fish.

From the above, the rate of recruitment (i.e. partial recruitment rate) can be considered to be equivalent to the age-specific maturation rate. If a time series of catch-per-unit-effort (CPUE) data is available, it is therefore possible to calculate the total instantaneous mortality rate $\left(Z_{t}\right)$ of a year-class from time $t$ to time $t+1$ by the equation

$$
Z_{t}=\ln \left\{\left(C P \cup E_{t} \times p_{t+1}\right) /\left(C P U E_{t+1} \times p_{t}\right)\right\}
$$

where CPUE $E_{t}$ and $C P U E_{t+1}$ are catch rates of a yearclass in years $t$ and $t+1$ respectively, $p_{t}$ is the mature proportion of a year-class during the autumn fishery in year $t$ (equivalent to partial recruitment rate) and therefore the proportion of the year-class that will spawn in the following summer, $p_{t+1}$ is the proportion of the same year-class that will be mature during the autumn fishery in year $t+1$, and $I n$ refers to natural logarithms.

The total instantaneous mortality rate of a cohort from time $t$ to time $t+1$ may also be defined as

$$
Z_{t}=-\ln \left(N_{t+1} / N_{t}\right)
$$

where $\mathrm{N}$ is comprised of both mature fish $(\mathrm{pN})$ and immature fish $((1-p) N)$. Therefore, if $S_{t}$ is the instantaneous spawning mortality rate in year $t$ and $M_{t}$ is the instantaneous natural mortality rate attributable to deaths other than spawning,

$$
\begin{gathered}
N_{t+1}=N_{t}\left\{p_{t} e^{-\left(M+S_{t}\right)}+\left(1-p_{t}\right) e^{-M}\right\} \\
=N_{t} e^{-M}\left\{p_{t} e^{-S_{t}}+\left(1-p_{t}\right)\right\} \\
\text { and } Z_{t}=M-\ln \left\{p_{t} e^{-s_{t}}+\left(1-p_{t}\right)\right\}
\end{gathered}
$$

Therefore, if $S_{t}, M$ and $p_{t+1}$ are known or assumed for a particular age-group, there is a unique solution of equations (1) and (2) for $Z$ and $p_{t}$. The estimation of

\begin{tabular}{|c|c|c|c|c|c|c|c|c|c|c|}
\hline \multirow{2}{*}{$\begin{array}{l}\text { Age } \\
(\mathrm{yr})\end{array}$} & \multicolumn{2}{|c|}{$1972-73$} & \multicolumn{2}{|c|}{$1973-74$} & \multicolumn{2}{|c|}{$1974-75$} & \multicolumn{2}{|c|}{$1975-76$} & \multicolumn{2}{|c|}{$1976-77$} \\
\hline & $A$ & $\mathrm{~S}$ & $A$ & $\mathrm{~S}$ & $A$ & $\bar{S}$ & $A$ & $\bar{S}$ & $A$ & S \\
\hline 3 & 12 & 2 & 25 & 31 & 20 & 40 & 62 & 61 & 9 & 2 \\
\hline 4 & 64 & 90 & 30 & 46 & 49 & 53 & 28 & 38 & 83 & 92 \\
\hline 5 & 21 & 8 & 40 & 20 & 18 & 5 & 8 & 1 & 7 & 5 \\
\hline $6+$ & 3 & 1 & 5 & 3 & 13 & 2 & 2 & 1 & 1 & 1 \\
\hline
\end{tabular}

TABLE 1. Percentage age compositions of capelin from the autumn fishery (A) in Div. $2 \mathrm{~J}$ and $3 \mathrm{~K}$ and the subsequent summer spawning population (S) in Div. 3K during 1972-77, with the autumn frequencies incremented by 1 year. these parameters is started on the oldest age-class of a cohort and the unique value of $p_{t}$ then becomes $p_{t+1}$ in the sequential computation of the cohort's maturation history.

To illustrate the calculation of maturation rates, assumptions were made concerning the values of $M$ and $p_{t+1}$. The natural mortality rate of capelin in the Northwest Atlantic is unknown, although an unsuccessful attempt was made to calculate $M$ by an Icelandic technique (Carscadden and Miller, MS 1980). Thus, for use in this paper, $M$ was assumed to be 0.3 for all age-groups.

Because the sequential calculation of maturation rate begins at the oldest age, $p_{t+1}$ for age 7 fish was assumed to be 1.0. This assumption appears to be valid in view of the absence of older fish in the catch-at-age data (see Table 3) and the mean length of older fish relative to the length-maturity ogives (Carscadden, 1978).

Estimated or assumed values of spawning mortality $\left(S_{t}\right)$ must also be available to calculate annual estimates of maturity. For use in this paper, age-specific $S_{t}$ values were estimated from equation (2) by using $Z$ values from Winters and Campbell (MS 1974). This type of calculation may appear to be somewhat circular because estimates of $p$ and $M$ are necessary to calculate $S_{t}$ from equation (2). However, this approach was considered to be justified for two reasons: (a) there are no estimates of spawning mortality and the empirically-derived estimates provide relative agespecific values, and (b) the values of $S_{t}$ are used only to illustrate the method of calculating maturation rates.

The effects of bias in the computed estimates of the proportions of mature capelin due to possible errors in the values of instantaneous natural mortality (M) and spawning mortality $\left(S_{t}\right)$ were examined for arbitrary changes of $\pm 33.3 \%$ in both $M$ and $S_{t}$.

Capelin samples from Canadian research vessel catches on the Grand Bank (Div. 3LNO) (Northwest Atlantic Fisheries Centre, St. John's, Nfld., unpubl. data) were used to estimate total mortality rates $\left(Z_{t}\right)$ for sexes combined after weighting by sex ratios (Table 2 ). Additional estimates of $Z_{t}$ were calculated from equation (1) with the use of USSR catch-at-age data (sexes

TABLE 2. Estimated total mortality rates $\left(Z_{t}\right)$ for capelin from unpublished Canadian and USSR sampling data, and agespecific spawning mortalities $\left(S_{t}\right)$ estimated from $p$-values of Winters and Campbell (MS 1974).

\begin{tabular}{lcccccc}
\hline & \multicolumn{3}{c}{ Estimated $Z_{\mathrm{t}}$ values } & & \multicolumn{2}{c}{$\mathrm{S}_{\mathrm{t}}$ values } \\
\cline { 1 - 2 } $\begin{array}{l}\text { Age } \\
(\mathrm{yr})\end{array}$ & $\begin{array}{c}\text { Canadian } \\
\text { data }\end{array}$ & $\begin{array}{c}\text { USSR } \\
\text { data }\end{array}$ & Mean & & $\begin{array}{c}\text { Age } \\
(\mathrm{yr})\end{array}$ & Mean \\
\hline $3-4$ & 0.73 & 0.60 & 0.67 & & 3 & 1.39 \\
$4-5$ & 2.11 & 1.17 & 1.64 & & 4 & 1.69 \\
$5-6$ & 2.23 & 2.83 & 2.53 & & 5 & 2.23 \\
\hline
\end{tabular}


combined) for Div. 3L(V. S. Bakanev, PINRO, Murmansk, pers. comm.) and the age-specific maturation rates of Winters and Campbell (MS 1974). The mean $Z_{t}$ values from the Canadian and USSR data (Table 2 ), the maturation rates $\left(p_{t}\right)$ of Winters and Campbell (MS $1974)$, and the assumed natural mortality rate ( $M=$ 0.30 ) were then used in equation (2) to derive agespecific spawning mortalities $\left(S_{t}\right)$. The value of 2.23 was assumed to be the spawning mortality of age 5 and older capelin.

The catches of capelin (numbers) by age-group for 1972-78 (Table 3) were derived from USSR sampling data (A. S. Seliverstov, PINRO, Murmansk, pers. comm.) and the catch rates were from Seliverstov and Serebrov (MS 1979). The 1979 catches by age-group were derived from data which were collected by Canadian observers aboard USSR fishing vessels.

\section{Results and Discussion}

For nearly all year-classes of capelin in Div. $2 \mathrm{~J}$ and $3 \mathrm{~K}$ (Table 4), the peak in CPUE occurred at age 3 (spawning age 4), which is the age at which most individuals of a year-class mature for spawning. Furthermore, the CPUE values were highest for ages 2-4 of the 1973 year-class, indicating that it was the strongest of the year-classes that were sampled during 1972-79.
Instantaneous total mortality rates $\left(Z_{t}\right)$, unadjusted for annual changes in partial recruitment, indicate that some year-classes may not be completely mature until age 7 (Table 4). The anomalous values of $Z_{t}$ for the older age-groups of the 1971 and 1972 yearclasses were probably due to errors in ageing the older fish and/or to inadequate sampling of age-groups 5 and 6 in 1977.

The age-specific maturation rates (Table 5), which correspond to the unique solutions of equations (1) and (2), were calculated from the CPUE data in Table 4, with the assumptions that natural mortality was 0.3 and that all 7-year-old capelin were fully mature. The maturation rates for each age-group varied considerably among year-classes. Such variation may not be surprising when one considers the probable influence of variable growth rates on maturation rates, and these growth rates may in turn be affected by a complex of factors which include large fluctuations in year-class size and variable hydrographic conditions. Nevertheless, the mean values increased progressively with age.

Although the present analysis was intended to be an illustration of how maturation rates can be derived from catch-per-unit-effort data, some guidance in evaluating the method was provided by means of estimates of the proportions of mature capelin from other sources. Such estimates (Table 6) were derived by

TABLE 3. Age composition of capelin catches (millions of fish) and catch-per-unit-effort (tons/hr) for the autumn fishery by USSR trawlers in Div. 2J and 3K, 1972-79.

\begin{tabular}{crrrrrrrr}
\hline \hline Age $(\mathrm{yr})$ & 1972 & 1973 & 1974 & 1975 & 1976 & 1977 & 1978 & 1979 \\
\hline 2 & 228.4 & $1,306.4$ & $1,015.2$ & $5,540.0$ & 789.7 & 157.0 & 247.5 & 355.5 \\
3 & $1,240.1$ & $1,538.8$ & $2,463.9$ & $2,486.9$ & $7,409.4$ & $1,578.1$ & 842.8 & 47.3 \\
4 & 406.4 & $2,085.3$ & 888.1 & 733.3 & 605.7 & $3,170.4$ & 574.8 & 11.0 \\
5 & 54.7 & 262.2 & 616.2 & 164.8 & 77.4 & 328.8 & 581.1 & 15.4 \\
6 & 7.2 & 14.2 & 49.3 & 43.0 & 16.3 & 45.1 & 28.3 & 14.2 \\
CPUE & 2.81 & 3.29 & 4.56 & 6.47 & 5.27 & 4.14 & 2.29 & 1.34 \\
\hline
\end{tabular}

TABLE 4. Catch-per-unit-effort (CPUE) and resultant total mortality rates $\left(Z_{t}\right)$ for the 196677 year-classes of capelin in the USSR autumn fishery in Div. $2 \mathrm{~J}$ and $3 \mathrm{~K}$ during 1972-79. (Mortality rates are unadjusted for annual changes in partial recruitment; add 1 year to obtain the spawning age for CPUE data.)

\begin{tabular}{|c|c|c|c|c|c|c|c|c|c|}
\hline \multirow{2}{*}{$\begin{array}{l}\text { Year- } \\
\text { class }\end{array}$} & \multicolumn{5}{|c|}{ CPUE by age-group (No. $\times 10^{-3} / \mathrm{hr}$ ) } & \multicolumn{4}{|c|}{$Z_{t}=\ln \left(C P \cup E_{t} / C P \cup E_{t+1}\right)$} \\
\hline & 2 & 3 & 4 & 5 & 6 & $2 / 3$ & $3 / 4$ & $4 / 5$ & $5 / 6$ \\
\hline 1966 & & & & & 0.45 & & & & \\
\hline 1967 & & & & 3.40 & 0.34 & & & & 2.30 \\
\hline 1968 & & & 25.25 & 6.32 & 1.77 & & & 1.39 & 1.27 \\
\hline 1969 & & 77.05 & 50.29 & 22.13 & 1.40 & & 0.43 & 0.82 & 2.76 \\
\hline 1970 & 14.19 & 37.11 & 31.90 & 5.37 & 0.40 & -0.96 & 0.15 & 1.78 & 2.60 \\
\hline 1971 & 31.51 & 88.51 & 23.91 & 1.88 & 1.23 & -1.03 & 1.31 & 2.54 & 0.42 \\
\hline 1972 & 36.47 & 81.06 & 14.75 & 8.97 & 1.23 & -0.80 & 1.70 & 0.50 & 1.99 \\
\hline 1973 & 181.03 & 180.51 & 88.53 & 22.59 & 1.97 & 0.00 & 0.74 & 1.34 & 2.44 \\
\hline 1974 & 19.23 & 43.07 & 25.07 & 2.14 & & -0.81 & 0.54 & 2.46 & \\
\hline 1975 & 4.29 & 36.75 & 1.53 & & & -2.15 & 3.18 & & \\
\hline 1976 & 10.79 & 6.56 & & & & 0.50 & & & \\
\hline 1977 & 49.28 & & & & & & & & \\
\hline
\end{tabular}


TABLE 5. Estimated maturation rates $\left(p_{t}\right)$ of the $1967-73$ cohorts of capelin in Div. $2 \mathrm{~J}$ and $3 \mathrm{~K}$, based on data from the USSR fishery in 1972-79.

\begin{tabular}{|c|c|c|c|c|}
\hline \multirow{2}{*}{$\begin{array}{l}\text { Year- } \\
\text { class }\end{array}$} & \multicolumn{4}{|c|}{ Maturation rates by age-group } \\
\hline & 3 & 4 & 5 & $\overline{6}$ \\
\hline 1967 & & & & 0.97 \\
\hline 1968 & & & 0.76 & 0.79 \\
\hline 1969 & & 0.48 & 0.67 & 1.00 \\
\hline 1970 & 0.12 & 0.47 & 0.89 & 1.00 \\
\hline 1971 & 0.19 & 0.83 & 0.93 & 0.57 \\
\hline 1972 & 0.22 & 0.80 & 0.56 & 0.93 \\
\hline 1973 & 0.34 & 0.62 & 0.80 & 0.99 \\
\hline Mean & 0.22 & 0.64 & 0.77 & 0.89 \\
\hline
\end{tabular}

using back-calculated lengths of capelin from Notre Dame Bay (Div. 3K) (Winter, 1982) and maturity ogives for capelin from the Grand Bank (Div. 3LNO) (Carscadden, 1978). The trends in maturation rates are similar, with relatively few capelin being mature at age 3 and all of the fish being mature at age 5 . In view of the assumptions relevant to calculation of the maturation rates in this paper and because both methods are subject to sampling error, the estimates in Table 6 are considered to support the method of estimating maturation rates from CPUE data.

Changes in assumed values of natural mortality (M) by $\pm 33.3 \%$ resulted in similar trends of $p_{t}$ for all year-classes (Fig. 2), there being a progressively larger effect on $\mathrm{p}_{\mathrm{t}}$ with decreasing age. The largest changes were for age-group 3 , with $p_{t}$ being overestimated by $10-17 \%$ for the decreased value of $M$ and underestimated by $8-14 \%$ for the increased value of $M$. The trend of increasing difference with decreasing age is probably connected with the sequential nature of the computations, with the calculations proceeding from the oldest to the youngest age-group.

Similar trends of increasing error in $p_{t}$ with decreasing age were exhibited by $\pm 33.3 \%$ changes in spawning mortlity $\left(S_{t}\right)$ (Fig. 3). The errors in $p_{t}$ were greater when $S_{t}$ was decreased than when $S_{t}$ was increased, the ranges being $16-18 \%$ and $8-10 \%$ respectively.

The analysis in this paper ignores the effect of fishing mortality in the calculation of $p_{t}$ values from the catch-curve generated $Z_{t}$ values. If the assumed value of $M$ is correct, the non-adjustment of $Z_{t}$ values to account for the effect of fishing mortality $(F)$ would lead to a positive bias in the estimates of $p_{t}$. Although $M$ was assumed to be constant in analyzing the 1972-79 capelin data, the major cod stock of the area (Div. $2 \mathrm{~J}+3 \mathrm{KL}$ ), which preys heavily on capelin (Winters and Carscadden, 1978), declined greatly during the same period (Wells, MS 1981). Thus, $M$ for capelin may have declined during the 1970's. However, exploitation of capelin increased substantially during this period, and
TABLE 6. Percentages of mature capelin by age based on backcalculated lengths in inshore samples from Div. $3 \mathrm{~K}$ and maturity ogives for samples from the Grand Bank.

\begin{tabular}{ccccccc}
\hline & \multicolumn{2}{c}{ Male } & & \multicolumn{2}{c}{ Female } & \\
\cline { 2 - 3 } $\begin{array}{c}\text { Age } \\
\text { (yr) }\end{array}$ & $\begin{array}{c}\text { Length } \\
(\mathrm{mm})\end{array}$ & $\begin{array}{c}\text { Percent } \\
\text { mature }\end{array}$ & & $\begin{array}{c}\text { Length } \\
(\mathrm{mm})\end{array}$ & $\begin{array}{c}\text { Percent } \\
\text { mature }\end{array}$ & $\begin{array}{c}\text { Sexes } \\
\text { combined }\end{array}$ \\
\hline 3 & 145 & $\sim 5$ & & 128 & $\sim 5$ & $\sim 5$ \\
4 & 170 & 55 & & 153 & 75 & 65 \\
5 & 189 & 100 & & 172 & 100 & 100 \\
6 & 202 & 100 & & 187 & 100 & 100 \\
\hline
\end{tabular}

this may have compensated for the decreased mortality due to cod predation. Therefore, the potential bias in the analysis, due to non-adjustment of $Z$ for fishing mortality (F), may not be significant, because $F$ could be considered as being included in the assumed $M$ value. Unfortunately, the effects of $F$ cannot be taken into account in greater detail because there are no independent estimates of fishing mortality.

Leggett et al. (1984) have contended that fishing mortality was not important in explaining trends in abundance of capelin during the 1970's. Part of their evidence was a comparison of catches and trends in abundance which were derived from sequential abundance models with the use of estimates of $p_{t}$ as derived in this paper. Therefore, their evaluation of fishing mortality is not relevant in the present context. However, the main results of their paper showed a correlation between year-class survival of capelin and environmental variables. They found that $58 \%$ of the variation in year-class strength could be explained by the frequency of onshore winds during the beach residence of larvae and temperature of the near-surface $(0-20 \mathrm{~m})$ water layer during 6 months after larval emergence. These results were obtained from data which were collected during the period of heaviest exploitation of capelin in the 1970's and indicate that more attention should be focused on estimating natural mortality rather than fishing mortality for use with the presented method of calculating proportions of mature capelin by age group.

The accuracy of maturation rates $\left(p_{t}\right)$ depends greatly on the catch-per-unit-effort and sampling data for which there are no estimates of variance. Ulltang (1980) noted that catch-per-unit-effort estimates from a pelagic fishery with gears other than purse-seine may provide better abundance indices, although data from aimed trawling may exhibit biases similar to those from a purse-seine fishery. One of the most common biases in purse-seine data involves the catchability of shoaling species, whereby catchability increases with declining stock size, and, as a result, catch-per-unit-effort does not decline and therefore does not reflect the status of the stock. The CPUE data for the capelin stock in Div. $2 \mathrm{~J}+3 \mathrm{~K}$ show considerable variation (fivefold change between the highest and lowest values), 


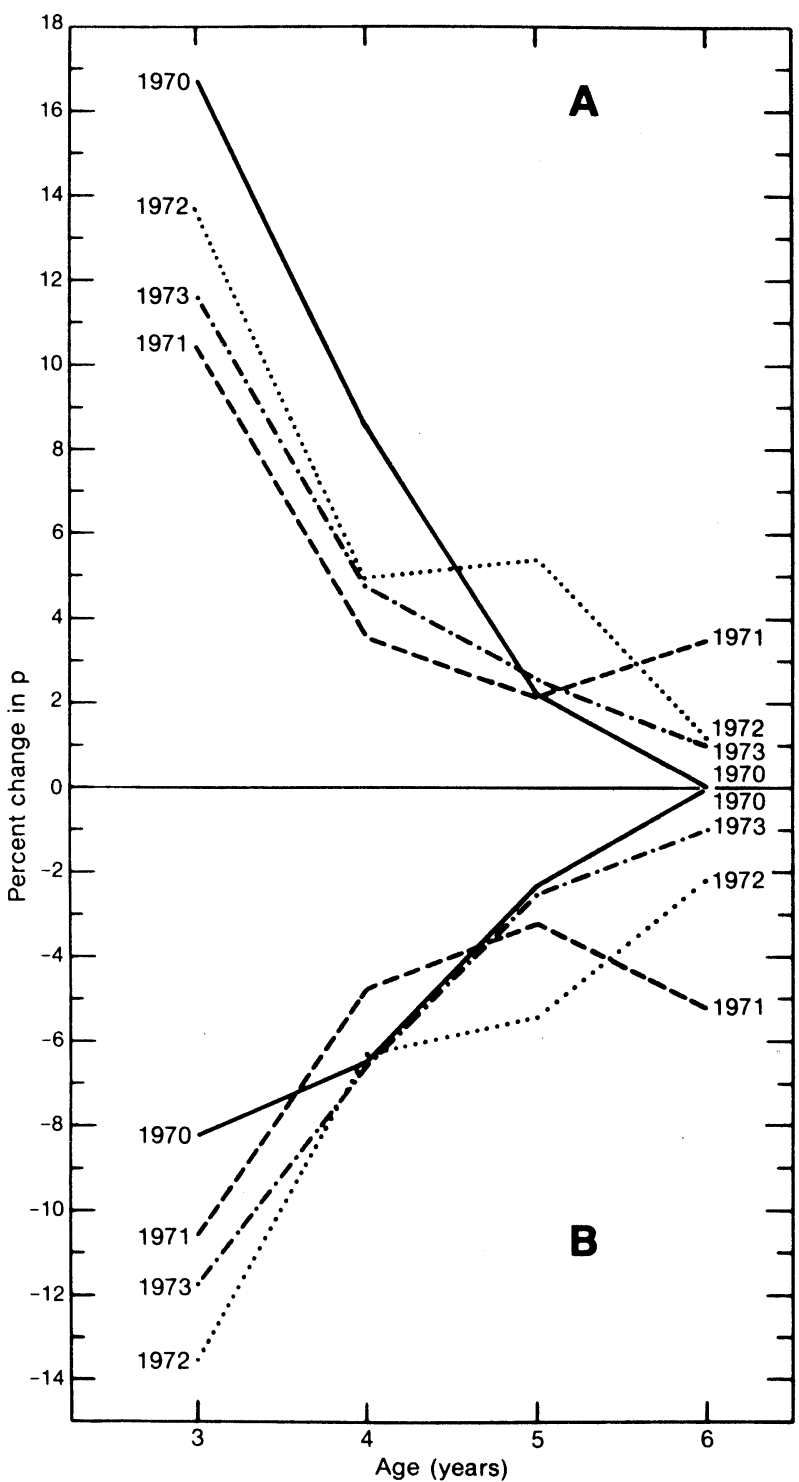

Fig. 2. Percent changes in proportion $\left(p_{t}\right)$ of mature capelin of the 1970-73 year-classes by age-group when natural mortality $(M)$ is reduced by one-third $(A)$ and increased by one-third (B).

indicating that these estimates may be a reasonable reflection of changes in the stock. In fact, these data have been used as abundance indices in assessing the capelin stocks (NAFO, 1983).

The sensitivity of the sequential computation model to changes in maturation rates $\left(p_{t}\right)$ are unknown. In an earlier version of the model (Miller and Carscadden, MS 1979), a change in $p_{t}$ of $1 \%$ resulted in a change of $2.8 \%$ in the total population. Thus, such models are potentially sensitive to changes in maturation rate, and this aspect will have to be addressed when evaluating the sequential computation model for capelin.

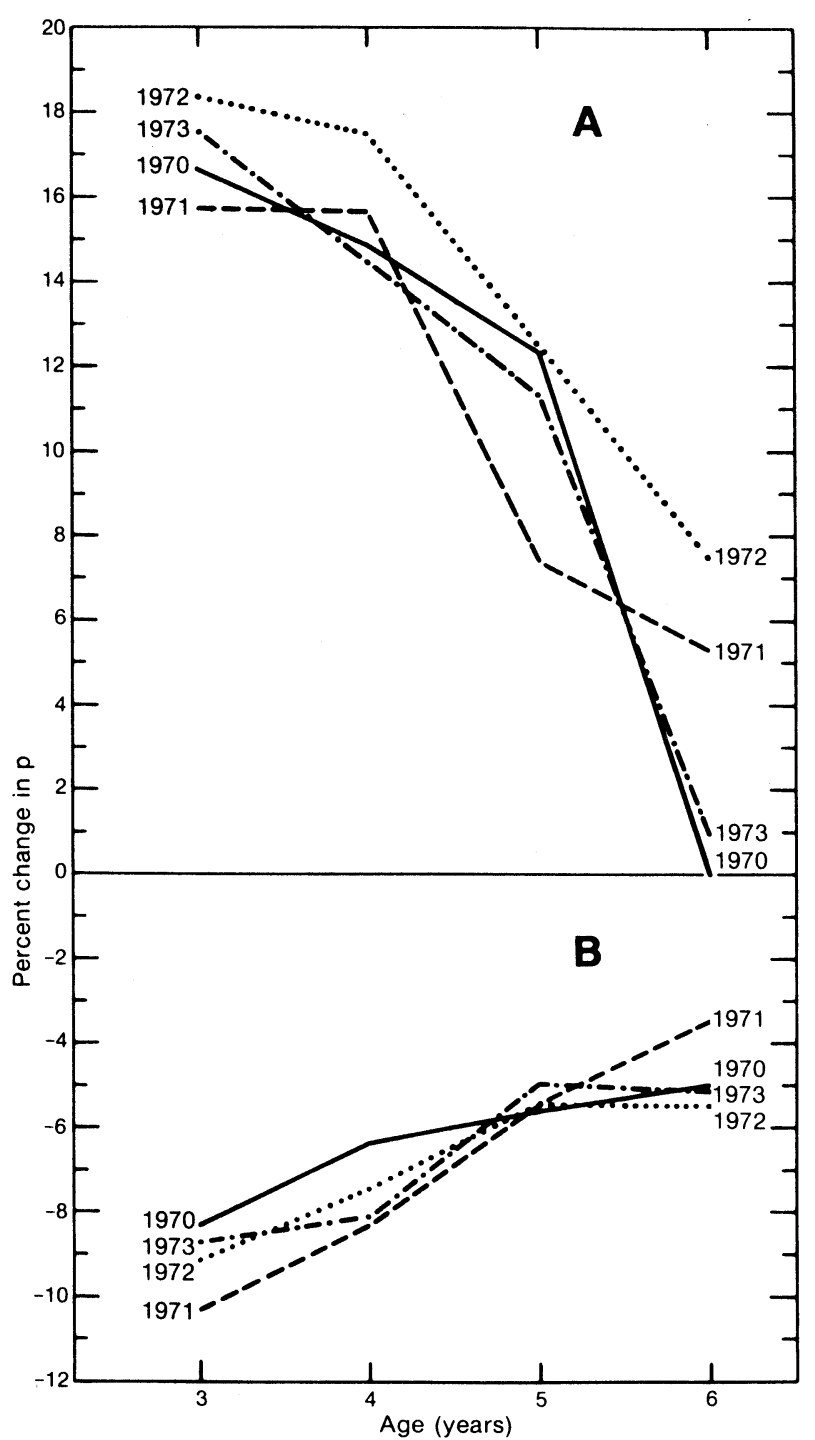

Fig. 3. Percent changes in proportions $\left(p_{t}\right)$ of mature capelin of the 1970-73 year-classes by age-group when spawning mortality $\left(S_{t}\right)$ is reduced by one-third $(A)$ and increased by one-third (B).

\section{References}

CARSCADDEN, J. E. 1978. The capelin, Mallotus villosus, population spawning on the Southeast Shoal of the Grand Bank, 1976. ICNAF Sel. Papers, 3: 61-71.

CARSCADDEN, J. E., and D. S. MILLER. MS 1979. Biological aspects of capelin and a sequential capelin abundance model for the Divisions 3LNO stock. ICNAF Res. Doc., No. 33, Serial No. 5359,20 p.

MS 1980. Estimation of natural mortality of Newfoundland capelin using the Icelandic method. NAFO SCR Doc., No. 45, Serial No. N077, 8 p.

KOVALYOV, S. M., and B. D. KUDRIN. 1973. Soviet investigations on capelin in the Northwest Atlantic. ICNAF Redbook, 1973(III): 121-126. 
LEGGETT, W. C., K. T. FRANK, and J. E. CARSCADDEN. 1984. Meteorological and hydrographic regulation of year-class strength in capelin (Mallotus villosus). Can. J. Fish. Aquat. Sci., 41: 1193-1201.

MILLER, D. S., and J. E. CARSCADDEN. MS 1979. Biological characteristics and biomass estimates of capelin in ICNAF Div. $2 \mathrm{~J}+3 \mathrm{~K}$ using a sequential capelin abundance model. ICNAF Res. Doc., No. 32, Serial No. 5358, 15 p.

NAFO. 1983. Capelin in Subareas 2 and 3. In Report of Scientific Council, June 1983 Meeting (p. 50-54). NAFO Sci. Coun. Rep., 1983, 151 p.

1984. Tabular summaries of nominal catches, 1968-82. NAFO Stat. Bull., 32: 17-22.

SELIVERSTOV, A. S., and L. I. SEREBROV. MS 1979. Status of capelin stocks in Divisions $2 \mathrm{~J}$ and $3 \mathrm{~K}$ in 1978. ICNAF Res. Doc., No. 30, Serial No. 5336, 12 p

ULLTANG, $Ф$. 1980. Factors affecting the reaction of pelagic fish stocks to exploitation and requiring a new approach to assessment and management. ICES Rapp. Proc.Verb., 177: 489-504.

WELLS, R. MS 1981. Status in 1980 of the cod stock in Divisions $2 J+3 K L$. NAFO SCR Doc., No. 66, Serial No. N350, $13 \mathrm{p}$.

WINTERS, G. H. 1982. Life history and geographical patterns of growth in capelin, Mallotus villosus, of the Labrador and Newfoundland areas. J. Northw. Atl. Fish. Sci., 3: 105-114.

WINTERS, G. H., and J. S. CAMPBELL. MS 1974. Some biological aspects and population parameters of Grand Bank capelin. ICNAF Res. Doc., No. 76, Serial No. 3309, $23 \mathrm{p}$.

WINTERS, G. H., and J. E. CARSCADDEN. 1978. Review of capelin ecology and estimation of surplus yield from predator dynamics. ICNAF Res. Bull., 13: 21-30. 